\title{
Exploring the Catalytic Significant Residues of Serine Protease Using Substrate-Enriched Residues and a Peptidase Inhibitor
}

\author{
Zahoor Khan ${ }^{1,2}$, Maryam Shafique ${ }^{2 *}$, Amir Zeb ${ }^{3,4}$, Nusrat Jabeen ${ }^{1}$, Sehar Afshan $\mathrm{Naz}^{2}$, and Arif Zubair ${ }^{5}$ \\ ${ }^{1}$ Department of Microbiology, University of Karachi 75270, Pakistan \\ ${ }^{2}$ Department of Microbiology, Federal Urdu University of Arts, Science and Technology, Karachi 75300, Pakistan \\ ${ }^{3}$ Division of Applied Life Science, Gyeongsang National University, Jinju 52828, Republic of Korea \\ ${ }^{4}$ College of Pharmacy and Graduate School of Pharmaceutical Sciences, Ewha Womans University, Seoul 03760, Republic of Korea \\ ${ }^{5}$ Department of Environmental Sciences, Federal Urdu University of Arts, Science and Technology, Karachi 75300, Pakistan
}

Received: September 28, 2020 / Revised: November 4, 2020 / Accepted: November 30, 2020

\begin{abstract}
Serine proteases are the most versatile proteolytic enzymes with tremendous applications in various industrial processes. This study was designed to investigate the biochemical properties, critical residues, and the catalytic potential of alkaline serine protease using in-silico approaches. The primary sequence was analyzed using ProtParam, SignalP, and Phyre2 tools to investigate biochemical properties, signal peptide, and secondary structure, respectively. The three-dimensional structure of the enzyme was modeled using the MODELLER program present in Discovery Studio followed by Molecular Dynamics simulation using GROMACS 5.0.7 package with CHARMM36m force field. The proteolytic potential was measured by performing docking with casein- and keratin-enriched residues, while the effect of the inhibitor was studied using phenylmethylsulfonyl fluoride, (PMSF) applying GOLDv5.2.2. Molecular weight, instability index, aliphatic index, and isoelectric point for serine protease were $39.53 \mathrm{kDa}, 27.79,82.20$ and 8.91 , respectively. The best model was selected based on the lowest MOLPDF score (1382.82) and DOPE score (-29984.07). The analysis using ProSA-web revealed a Z-score of -9.7 , whereas $88.86 \%$ of the residues occupied the most favored region in the Ramachandran plot. Ser327, Asp138, Asn261, and Thr326 were found as critical residues involved in ligand binding and execution of biocatalysis. Our findings suggest that bioengineering of these critical residues may enhance the catalytic potential of this enzyme.
\end{abstract}

Keywords: Catalytic potential, serine protease, caseinolytic, keratinolytic, modeling

\section{Introduction}

Bacillus tequilensis has recently emerged as an ideal candidate to produce extracellular enzymes having numerous potential commercial applications [1]. Alkaline protease from Bacillus tequilensis P15 demonstrated effective destaining, dehairing and gelatinolytic potentials [2]. Similarly, a novel keratinase from Bacillus tequilensis Q7 showed excellent dehairing and bating potential [3].

\section{*Corresponding author}

Tel: +92-300-5266109

E-mail:maryamshafique@yahoo.com
Alkaline protease from Bacillus tequilensis ZMS-2 exhibited multifarious commercial catalytic potential including fibrinolytic, antimicrobial, anti-coagulant, caseinolytic, fibrinolytic and dehairing potentials [1].

Microbial proteases represent a commercially viable group of hydrolytic enzymes which catalyze protein into small peptides and/or free amino acids. They are highly desirable in industries such as leather processing, detergent manufacturing, food and feed production, peptide synthesis, photography, silk degumming and waste management [4]. Thus, have a market share of over $65 \%$ in global enzyme market [5]. Proteases are classified 
into various groups based on residues in their active sites and catalytic mechanisms. This includes serine proteases, cysteine proteases, aspartic proteases, metalloproteases, threonine protease, glutamic protease, and asparagine protease $[4,6]$. Serine proteases are characterized by the presence of serine residue at their active sites. The catalytic triad of serine exopeptidases and endopeptidases is composed of His (base), Asp (electrophile) and Ser (nucleophile). Catalysis by serine protease is processed in two steps: In first step, the serine residue and substrate form an acyl-enzyme intermediate. In the second step, the water molecule hydrolyzes the acylenzyme intermediate to release the peptide [6]. The main reason behind the growing interest in microbial serine proteases in the last decade is their applications mainly in leather tanning, detergent formulation and diagnostics [7].

Keratin is an insoluble, high sulfur-containing protective protein constituting the bulk of epidermal appendages such as hair, nails, claws, turtle scutes, horns and feathers. Keratin hydrolysate has vast commercial applications in regenerative medicine materials, tissue engineering, in the production of keratin-based coatings and as fibers in polymer reinforcements [8]. Hair is mainly composed of $\alpha$-keratin, having high abundance of alanine, leucine, arginine and cysteine [9]. Casein is a complex milk protein composed of $\alpha_{\mathrm{S}^{-}}, \alpha_{\mathrm{S} 2^{-}}, \beta-, \mathrm{k}$-casein and colloidal phosphate calcium [10]. Commercial applications of casein include its use as binding material in plastics industry, in synthesis of cotton fibers and as stabilizer in food industry $[11,12]$. Bovine casein contains highest fractions of leucine, lycine, isoleucine and valine residues [13].

Bioinformatics tools can reveal catalytic potentials and ligand binding specificities of target enzyme erstwhile proceeding towards its bulk production at industrial level. Similarly, molecular docking studies help us to predict noncovalent interactions, conformation and binding affinity by characterizing the behavior of ligand molecule(s) in catalytic site of the target protein [14]. Furthermore, improved force fields, motions on the micro-second, and scale processes (protein folding) of Molecular Dynamics (MD) simulation has potential to study spatial and temporal resolution of target protein [15]. This study unveils the biochemical properties, catalytic potentials and binding patterns of an alkaline ser- ine protease using in-silico techniques.

\section{Material and Methods}

\section{Primary structure and biochemical properties}

As the 3D structure of alkaline serine protease (ASP) from Bacillus tequilensis was not available in Protein Data Bank (PDB), thus, the primary sequence of ASP was obtained from NCBI (GenBank: SPT94135.1). The biochemical properties and Signal peptide for this sequence were investigated using online ProtParam tool [16] and SignalP 5.0 [17], respectively.

\section{Prediction of secondary structure}

Phyre2 (Protein Homology/analogy Recognition Engine $\mathrm{V}$ 2.0) program was implied to predict the secondary structure for the target enzyme. This online program uses the self-optimized prediction method (SOPM) to increase the second-order forecast improvement rate based on the primary sequence [18].

\section{Identification of conserved sequences}

The amino acids sequence alignment was carried out using UniProt-BLAST to identify the sequences having highest level of similarity with ASP. Top 5 sequences having more than $90 \%$ identity with ASP were then subjected to Multiple Sequence Alignment using CLUSTAL Omega (1.2.4) algorithm in EMBL-EBI to identify conserved residues followed by construction of phylogenetic tree.

\section{Homology modeling and identification of critical residues}

The primary sequence of ASP was used to identify the best fitted template proteins using basic local alignment search tool for proteins (BLAST-P) and position-specific iterated basic local alignment search tool (PSI-BLAST) in NCBI. During the Protein BLAST, the primary sequences of target serine protease showed highest level of similarity and e-value with the crystallographic structure of subtilisin (PDB ID: 1SBN) from Bacillus subtilis. Hence, the aligned sequence of target-template proteins was subjected to MODELLER program in Discovery Studio and ten models were generated.

\section{Model validation}

The most suitable model was subjected to MD simula- 
tion and energy minimization to obtain the native conformation of the final model. The MD simulation was performed by GROMACS 5.0.7 package with CHARMM36mforce field [19]. The simulation system was prepared in octahedral box with TIP3P water model and neutralized by $0.1 \mathrm{M} \mathrm{NaCl}$ solution. The simulation was equilibrated in two steps: NVT equilibration was carried out for $100 \mathrm{ps}$ at $300 \mathrm{~K}$, while the NPT equilibration was performed for $100 \mathrm{ps}$ at 1.0 bar pressure. NVT and NPT equilibrations were carried out by V-rescale and Parrinello-Rahman barostat, respectively. The production ensemble was carried out for $10 \mathrm{~ns}$ under the periodic boundary condition with LINCS algorithm. The stereochemical quality and accuracy of the MD-refined model was validated by ProSA-web $[20,21]$ and the RAMPAGE [22].

\section{Molecular docking studies}

Genetic optimization of ligand docking (GOLD v5.2.2) [23], was used for molecular docking studies of ASP with designated ligands. The modeled protease was used as receptor while amino acids residues (mimicking the binding site of casein and keratin) and PMSF (inhibitor) were prepared as ligands. The binding site of modeled protein was traced from its catalytic site residues and superimposed over the template structure. A total of fifty conformers were generated for each ligand molecule in the binding site of modeled protease via Genetic Algorithm (GA) module implanted in GOLD package. Finally, the best fitted pose of each ligand was selected based on highest ChemPLP score, conformational stability and hydrogen bond interactions with the active site residues of the modeled protein. The docking results were analyzed by Discovery Studio and GOLD package.

\section{Results and Discussion}

\section{Primary structure and biochemical properties}

Analysis by ProtParam revealed that the ASP was a polypeptide of 381 amino acids residues having an estimated molecular weight of $39.53 \mathrm{kDa}$. The estimated half-life was 30 hours (mammalian reticulocytes, in vitro), $>20$ hours (yeast, in vivo) and >10 hours (Escherichia coli, in vivo). Furthermore, the instability index was computed to be 27.79 , which suggests that the enzyme is stable. The aliphatic index, the Grand aver- age of hydropathicity (GRAVY) and the isoelectric point for the enzyme were calculated as $82.20,-0.081$ and 8.91 , respectively.

\section{Signal peptide prediction}

Signal peptide for the ASP was predicted using SignalP 5.0, which revealed a cleavage site between residue at position no. 29 and 30 with a probability of 0.8903 (Fig. 1). Similarly, the likelihood scores for signal peptide (Sec/SPI), TAT signal peptide (Tat/SPI) and lipoprotein signal peptide (Sec/SPII) were 0.9893, 0.0026 and 0.0065 , respectively.

\section{Prediction of secondary structure}

The secondary structure of the ASP was predicted by applying Phyre2 program utilizing SOPMA method [18]. The results revealed that the secondary structure of ASP from Bacillus tequilensis was composed of $28 \% \alpha$ helix, 25\% $\beta$-sheet (Fig. 1). A similar study reported $27 \%$ $\alpha$-helix and $26 \% \beta$-sheet in the secondary structure of keratinase from Bacillus mojavensis [24].

\section{Homology modelling and critical residues}

During homology modelling, the sequence alignment of the target protein showed high sequence similarity with the crystal structure of subtilisin (PDB ID: 1SBN) from Bacillus subtilis with presence of serine residue in the catalytic pocket classifying it as serine protease (Fig. $2 \mathrm{~A})$. The comparative analysis of both the sequences suggested that Asp138, Asn261, Thr326, and Ser327 are the critical residues of the target sequence involved in ligand binding and catalysis.

\section{Structure development}

The crystal structure of subtilisin from Bacillus subtilis was used as template for the homology modeling of ASP. Among the ten models generated by MODELLER program, the best model of target protein was selected based on the lowest molecular probability density function (MOLPDF) score (1382.82) and DOPE score (-29984.07).

\section{Structure validation}

The representative structure for serine protease was extracted after MD simulation refinement (Fig. 2B). Upon superimposition of the MD-refined serine protease 


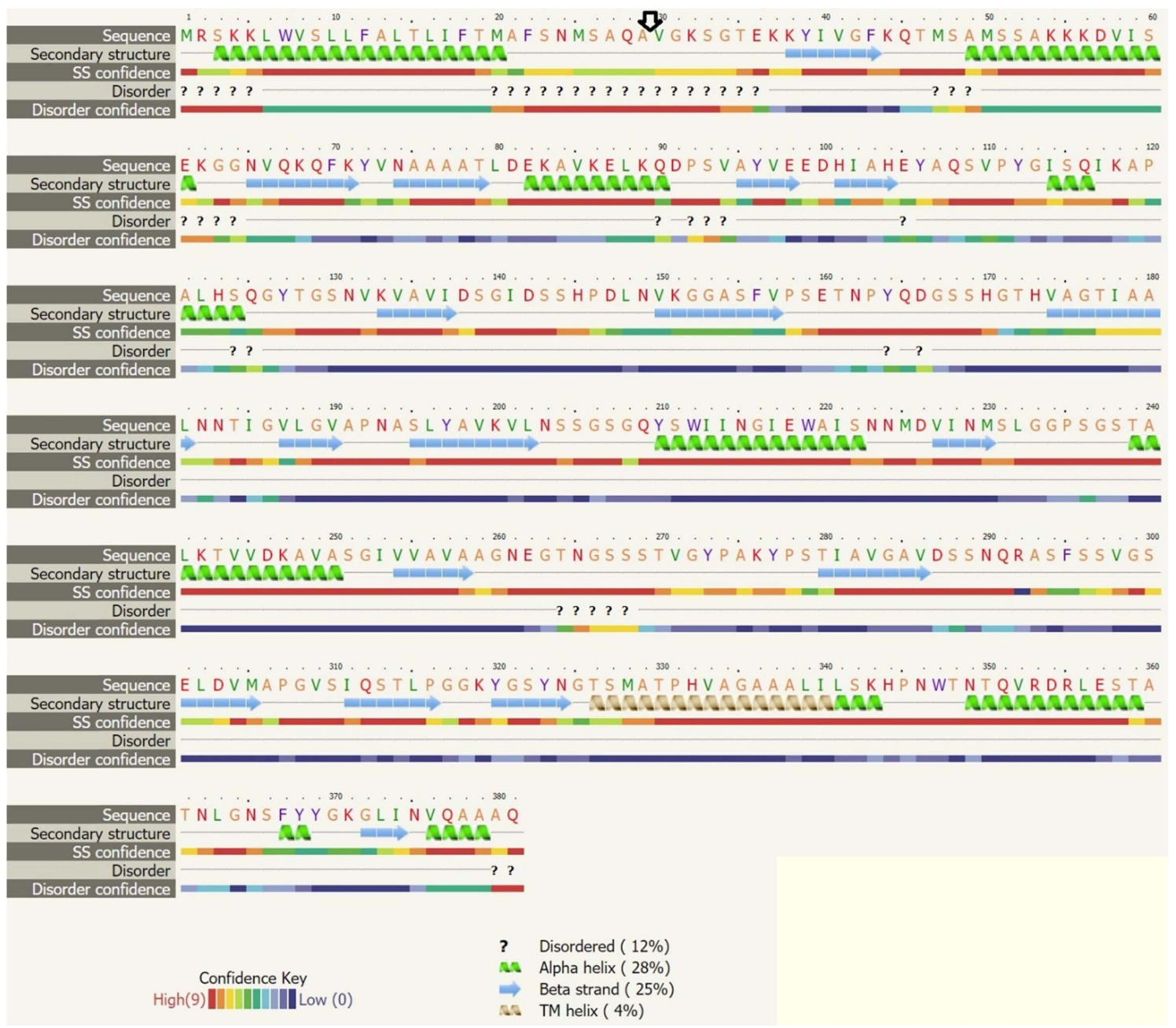

Fig. 1. Phyre2 analysis of ASP displaying $\boldsymbol{\alpha}$-helix and $\boldsymbol{\beta}$-sheet. The black arrow showing a cleavage site between residue at position no. 29 and 30 predicted using SignalP 5.0

and its template structure (PDB ID: 1SBN) suggested that serine protease also folded in identical 3D structure (Fig. 2C). The modelled protease folded in native conformation like other serine proteases. The stereo-chemical quality of the refined structure revealed that $88.86 \%$ of the residues occupied the most favored region of the Ramachandran plot (Fig. 2D). These results suggest that phi $(\phi)$ and psi $(\psi)$ backbone dihedral angles in the modeled structure are reasonably accurate. Analysis of the structure by ProSA-web revealed a Z-score of -9.7, which was within the range of Z-scores of experimentally determined structures (Fig. 2E).

\section{Molecular docking studies}

The interaction pattern of the docked ligands sug- gested that each ligand formed a hydrogen bond $(\mathrm{H}-$ bond) interaction with Ser327 of the serine protease (Figs. 5-7). A similar binding of ligand residues in the substrate binding site has been reported by previous studies [25, 26]. The formation of $\mathrm{H}$-bond at such residue is essentially important in ensuring effective binding of the enzyme with ligand. The establishment of several Hbonds with other residues of the target protein ensured tight binding of ligand with target protein is in strong coherence with earlier studies [25, 27]. Apart from that, each ligand molecule also formed Van der Waals/hydrophobic interactions with the catalytic pocket residues of the target protein resulting a more workable binding (Table 1). Current study also foresees that modification of residues in the catalytic triad can help to enhance the 


\section{A}

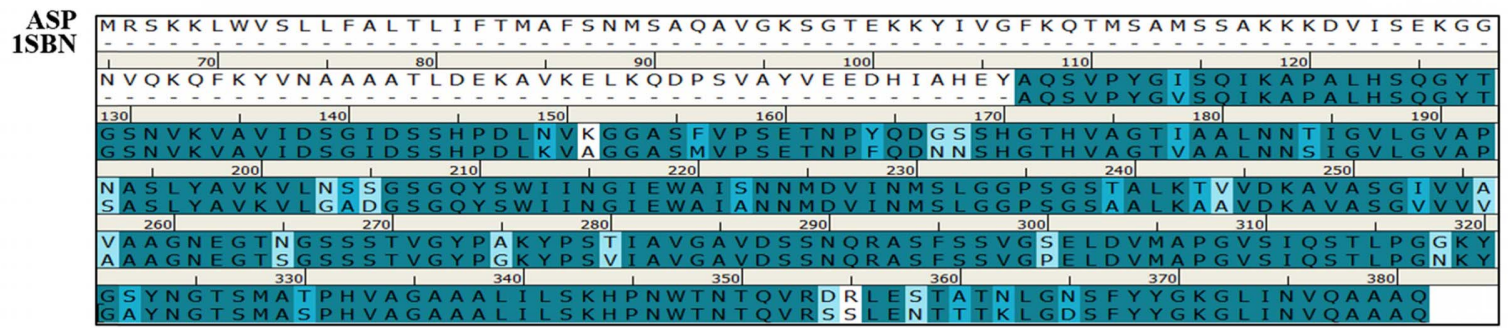

B

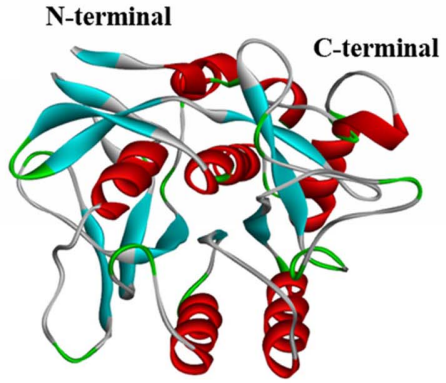

Target Protein Model

\section{D}

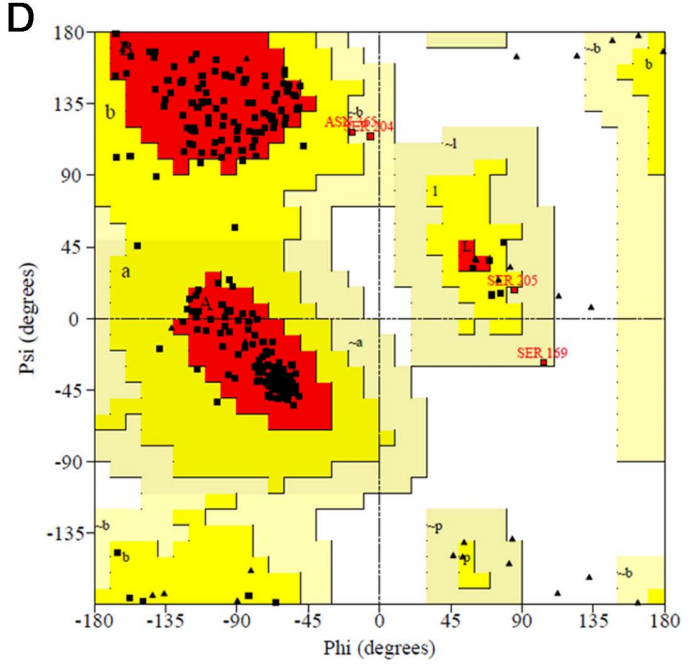

C

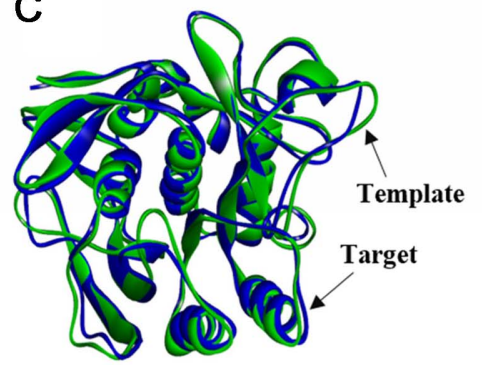

Target-template superimposition

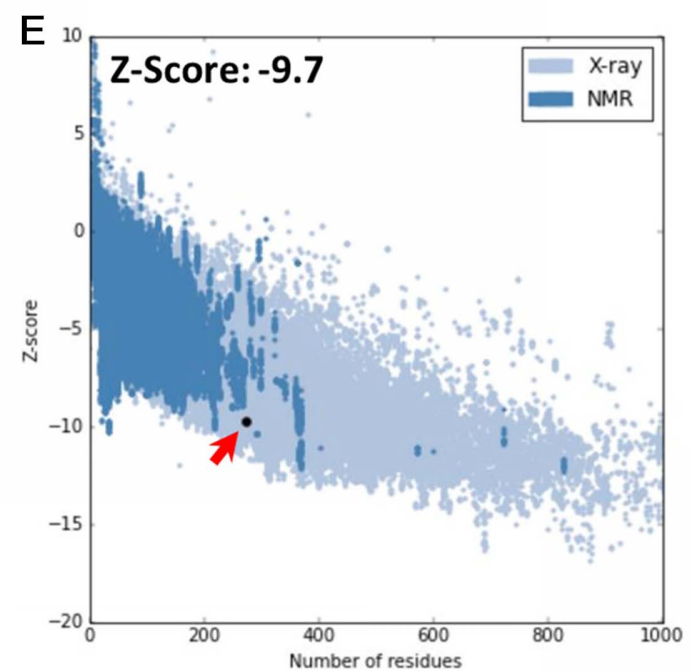

Fig. 2. Homology modelling and model validation of ASP. (A) Sequence alignment of ASP with ISBN. (B) Ribbon diagram of ASP. (C) Ribbon diagram of ASP and ISBN superimposition. (D) Ramachandran plot, showing $88.86 \%$ of the residues occupied the most favored region. (E) Analysis of ASP structure by ProSA-web revealing a Z-score of -9.7.

catalytic efficiency and substrate specificity of serine protease [27]. All these data suggested that each ligand molecule could potentially bind the substrate binding site of serine protease and may facilitate either the catalytic activity or inhibit the target protein.

\section{Docking studies with keratin enriched residues}

The interaction of alanine residue in the catalytic site of modelled protease was favored by $4 \mathrm{H}$-bonds with Ser205, Ser327, Gly206 and Asp138 resulting a docking score of $-31.15 \mathrm{~kJ} / \mathrm{mol}$. This binding was further stabilized by hydrophobic/Van der Waals interactions of Ser231, Leu202, His170, Gly171, and Ser204. The binding of leucine residue with a docking score of $-36.11 \mathrm{~kJ} /$ mol was improved by Thr326, Ser327, Asn261 and Asn324 through H-bonding and further supported by 
A

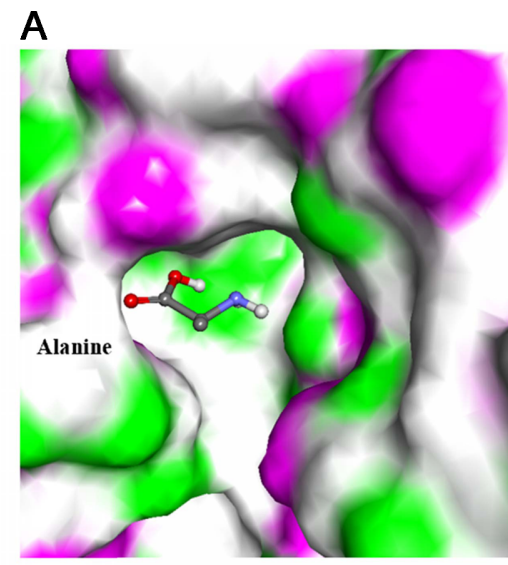

D

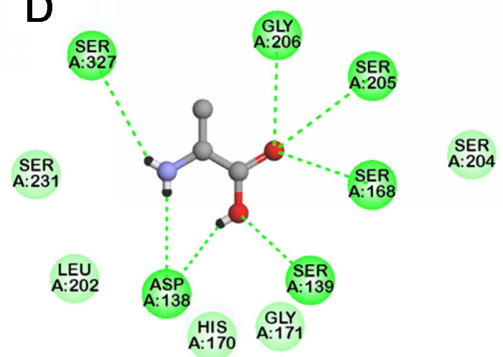

B

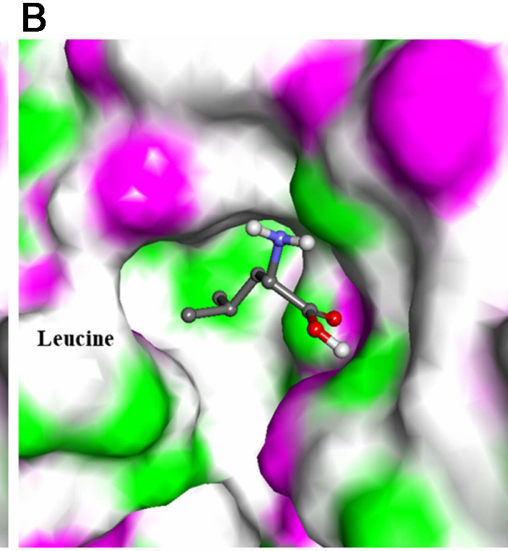

$\mathrm{E}$

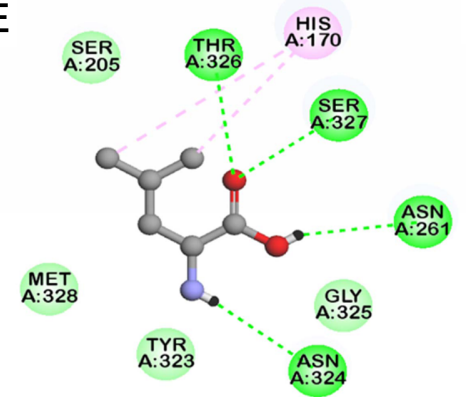

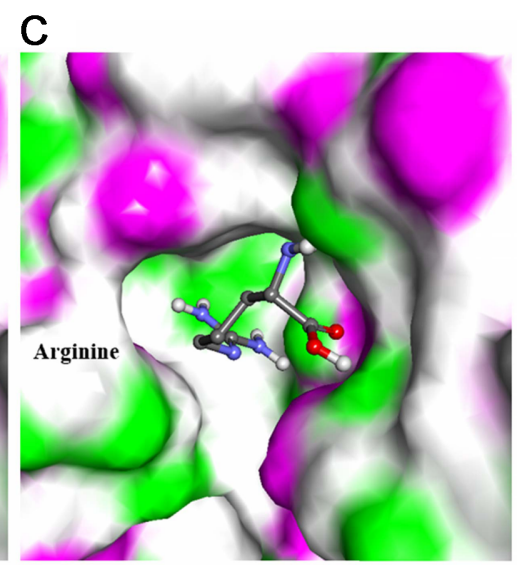

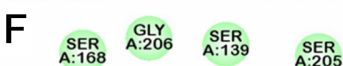

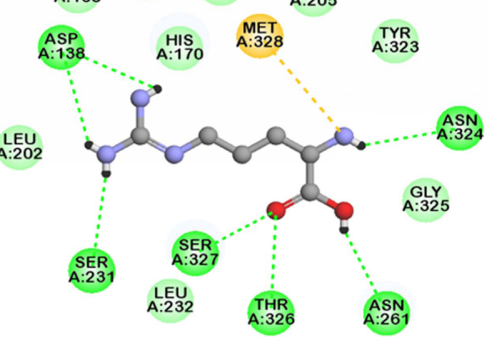

Fig. 3. Molecular orientation and binding pattern of keratin enriched residues with ASP. (A-C) Depict the 3D orientation of alanine, leucine, and arginine residues from substrate (keratin) in the substrate binding site of ASP. (D-F) Depict the 2D interactions pattern of alanine, leucine, and arginine with ASP. The interacting residues of ASP are portrayed and labelled. The substrate residues are represented as ball and stick models. Hydrogen bonds are depicted as dashed lines.

hydrophobic/Van der Waals interactions involving Ser205, Met328, Tyr323, Gly325 and His170. Arginine was bound with a dock score of $-44.74 \mathrm{~kJ} / \mathrm{mol}$ due to $6 \mathrm{H}$ bonds favored by Asp138, Ser231, Ser327, Thr326, Asn261 and Asn324 and hydrophobic/Van der Waals interactions by Leu232, Gly325, Tyr323, Ser205, Ser139, Gly206, Ser168 and Leu202 (Fig. 3).

The binding affinity and dock score of ASP with keratin enriched residues suggests its catalytic potential towards keratin. This keratinolytic potential of protease can be well exploited for dehairing during leather processing. Proteases with keratinolytic/dehairing potential have been reported previously [1,28] which can serve as effective tools for the replacement of notorious chemicals conventionally in use. During the process of enzymatic dehairing, proteases attack the basal cells of the hair bulb along with cells of malphigian layer tailed by slackening of hair and breakdown of the inner root sheath as well as the non-keratinized parts of hair [29]. It is noteworthy that not all proteases are applicable for dehairing because of their collagenolytic activity [30]. Therefore, such proteases having high keratinolytic and no or low collagenolytic activity are ideal for industrial application [31]. These proteases selectively degrade the soft keratin tissue in the follicle, thereby pulling out intact hairs without affecting tensile strength of the leather [32]. The use proteases in dehairing support the elimination of lime and sodium sulfide, helping to minimize the problem of stream pollution in addition to improved leather quality [33]. The ASP from Bacillus tequilensis showed excellent catalytic potential toward keratin substrate during docking studies and this potential may be further confirmed during empirical studies to use it as a better alternative in deharing.

\section{Docking studies with casein enriched residues}

The best docking pose for lysine residue established a dock score of $-41.26 \mathrm{~kJ} / \mathrm{mol}$ supported by $6 \mathrm{H}$-bonds with Asp138, Ser327, Thr326, Asn261 and Asn324 residues of the ASP. Moreover, non-H bond interactions for this 

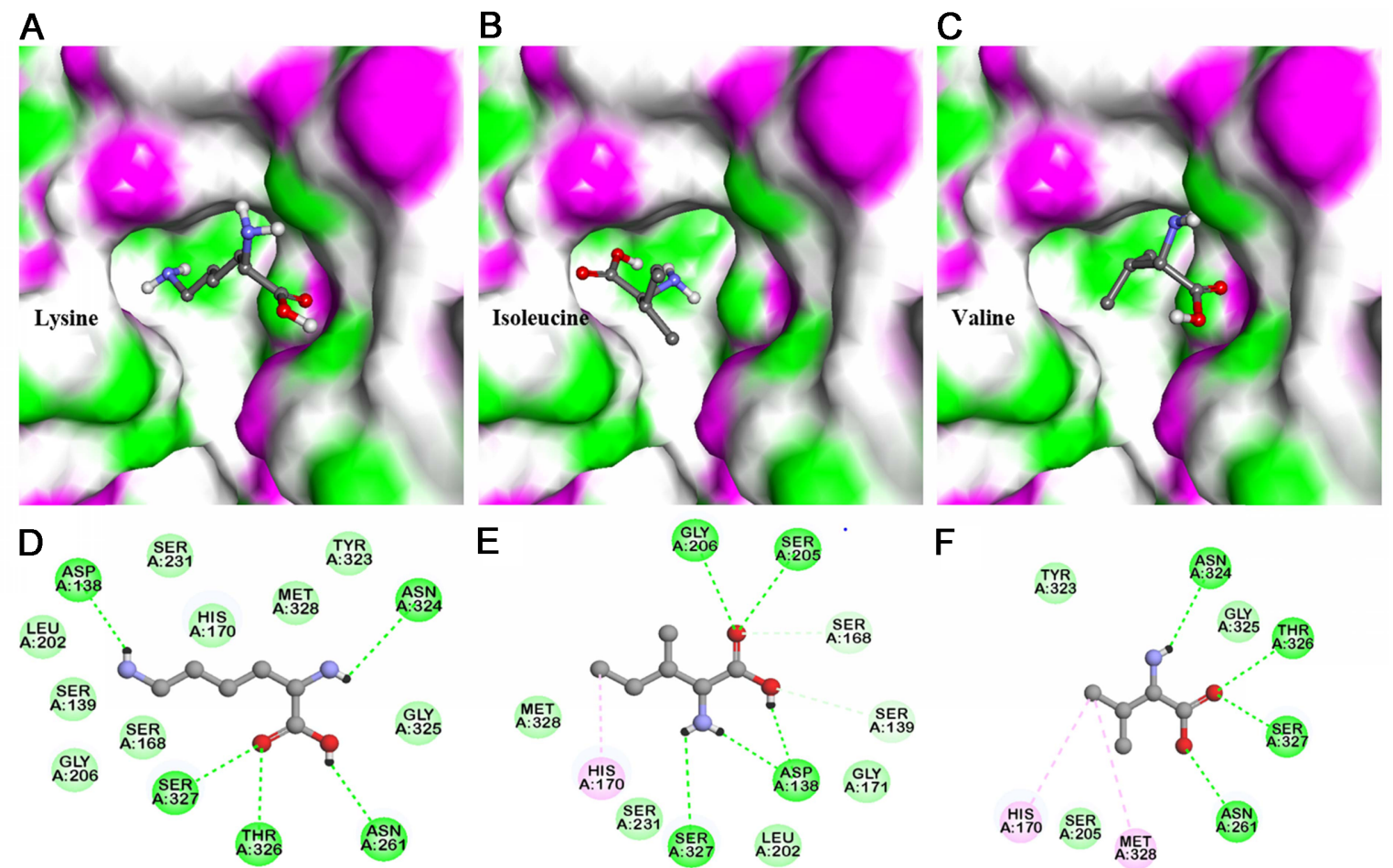

Fig. 4. Molecular orientation and binding pattern of casein enriched residues with ASP. (A-C) Represent the 3D orientation of lysine, isoleucine, and valine residues from substrate (casein) in the substrate binding site of ASP (D-F) Depict the 2D interactions pattern of lysine, isoleucine, and valine and ASP. The interacting residues of ASP are portrayed and labelled. The substrate residues are portrayed as ball and stick models. Hydrogen bonds are depicted as dashed lines.

ligand involved Leu202, Ser139, Ser168, Gly206, Gly325, Tyr323, Met328, His170 and Ser231. Isoleucine was bound in the catalytic triad with $4 \mathrm{H}$-bonds (Gly206, Ser205, Asp138 and Ser327) and hydrophobic/Van der Waals interactions (Met328, His170, Leu202, Gly171, Ser139 and Ser168) portraying the dock score of -34.77 $\mathrm{kJ} / \mathrm{mol}$. Similarly, valine with a dock score of $-30.63 \mathrm{~kJ} /$ mol was bound using H-bonds (Asn324, Thr326, Asn261 and Ser327) and hydrophobic/Van der Waals interactions (Tyr323, His170, Ser205, Met328 and Gly325) with the modelled structure of ASP (Fig. 4).

The caseinolytic potential of a protease is very ideal for its potential commercial applications in food and pharmaceutical industries. During casein hydrolysis, protease cleaves the peptide bonds within the polypeptide chains of complex structure of casein, leading to generation of peptides of varying length [34]. The caseinolytic potential of protease has immense commercial important as casein hydrolysates are used as calcium binding peptides [35] and as stabilizers in food industry [12]. The ASP from Bacillus tequilensis showed affinity and binding specificity towards casein enriched residues as observed during in-silico studies, pointing towards its confirmation through empirical studies and potential applications in relevant industries.

\section{Docking studies with PMSF}

In case of PMSF, 3 H-bonds (Asn261, Thr326 and Ser327) were observed with the target protein resulting a dock score of $-37.64 \mathrm{~kJ} / \mathrm{mol}$. The same bonding of PMSF with Serine residue is reported in previous studies leading to complete inactivation of target protease $[25,26]$. Furthermore, a significant number of hydrophobic/Van der Waals interactions were recorded between PMSF and the modelled structure of serine protease (Table 1). These interactions between ASP and PMSF interactions collectively result into the inhibition catalytic activity of enzyme (Fig. 5). 
Table 1. Docking score and binding pattern of substrates residues and PMSF with ASP.

\begin{tabular}{|c|c|c|c|c|c|c|c|}
\hline \multirow{2}{*}{$\begin{array}{c}\text { Ligand } \\
\text { amino } \\
\text { acid }\end{array}$} & \multirow[b]{2}{*}{$\begin{array}{l}\text { Dock } \\
\text { score }\end{array}$} & \multicolumn{4}{|c|}{$\mathrm{H}$ bonds } & \multirow[b]{2}{*}{ Hydrophobic Interactions } & \multirow[b]{2}{*}{ Van der Waals Interactions } \\
\hline & & $\begin{array}{l}\text { Amino } \\
\text { acid }\end{array}$ & $\begin{array}{l}\text { Amino acid } \\
\text { atom }\end{array}$ & $\begin{array}{l}\text { Ligand } \\
\text { atom }\end{array}$ & $\begin{array}{l}\text { Length } \\
(\AA \AA)\end{array}$ & & \\
\hline \multirow{4}{*}{ Alanine } & \multirow{4}{*}{-31.15} & Ser205 & $\mathrm{HN}$ & $\mathrm{O} 2$ & 2.5 & \multirow{4}{*}{ Leu202, His170, Gly171 } & \multirow{4}{*}{ Ser231, His170, Ser204 } \\
\hline & & Ser327 & OG & $\mathrm{H} 12$ & 2.6 & & \\
\hline & & Gly206 & $\mathrm{HN}$ & $\mathrm{O} 2$ & 2.1 & & \\
\hline & & Asp138 & OD1 & $\mathrm{H} 13$ & 1.5 & & \\
\hline \multirow{4}{*}{ Leucine } & \multirow{4}{*}{-36.11} & Thr326 & $\mathrm{HN}$ & $\mathrm{O} 2$ & 2.2 & \multirow{4}{*}{$\begin{array}{c}\text { Ser205, Met328, Gly325, } \\
\text { His170 }\end{array}$} & \multirow{4}{*}{ Ser205, Tyr323, Gly325, His170 } \\
\hline & & Ser327 & $\mathrm{HN}$ & $\mathrm{O} 2$ & 2.0 & & \\
\hline & & Asn261 & OD1 & $\mathrm{H} 22$ & 2.1 & & \\
\hline & & Asn324 & $\mathrm{O}$ & $\mathrm{H} 20$ & 2.1 & & \\
\hline \multirow{6}{*}{ Arginine } & \multirow{6}{*}{-44.74} & Asp138 & OD1 & $\mathrm{H} 24$ & 2.1 & \multirow{6}{*}{$\begin{array}{l}\text { Leu232, Tyr323, Ser205, } \\
\text { Gly206, Ser168 }\end{array}$} & \multirow{6}{*}{$\begin{array}{l}\text { Gly325, Ser205, Ser139, } \\
\text { Gly206, Ser168, Leu202 }\end{array}$} \\
\hline & & Ser231 & $\mathrm{O}$ & $\mathrm{H} 23$ & 2.2 & & \\
\hline & & Ser327 & $\mathrm{HN}$ & $\mathrm{O} 2$ & 2.0 & & \\
\hline & & Thr326 & $\mathrm{HN}$ & $\mathrm{O} 2$ & 2.1 & & \\
\hline & & Asn261 & OD1 & $\mathrm{H} 22$ & 2.0 & & \\
\hline & & Asn324 & $\mathrm{O}$ & $\mathrm{H} 21$ & 2.0 & & \\
\hline \multirow{5}{*}{ Lysine } & \multirow{5}{*}{-41.26} & Asp138 & OD1 & $\mathrm{H} 23$ & 1.7 & \multirow{5}{*}{$\begin{array}{l}\text { Leu202, Gly206, Gly325, } \\
\text { Tyr323, Met328, Ser231 }\end{array}$} & \multirow{5}{*}{$\begin{array}{c}\text { Ser139, Ser168, Met328, His170, } \\
\text { Ser231 }\end{array}$} \\
\hline & & Ser327 & $\mathrm{HN}$ & $\mathrm{O} 2$ & 2.0 & & \\
\hline & & Thr326 & $\mathrm{HN}$ & $\mathrm{O} 2$ & 2.1 & & \\
\hline & & Asn261 & OD1 & $\mathrm{H} 24$ & 2.0 & & \\
\hline & & Asn324 & $\mathrm{O}$ & $\mathrm{H} 21$ & 2.2 & & \\
\hline \multirow{4}{*}{ Isoleucine } & \multirow{4}{*}{-34.77} & Gly206 & $\mathrm{HN}$ & $\mathrm{O} 2$ & 2.2 & \multirow{4}{*}{ Met328, Ser139, Ser168 } & \multirow{4}{*}{ His170, Leu202, Gly171, Ser139 } \\
\hline & & Ser205 & $\mathrm{HN}$ & $\mathrm{O} 2$ & 2.5 & & \\
\hline & & Asp138 & OD1 & $\mathrm{H} 20$ & 1.7 & & \\
\hline & & Ser327 & OG & $\mathrm{H} 21$ & 2.9 & & \\
\hline \multirow{4}{*}{ Valine } & \multirow{4}{*}{-30.63} & Asn324 & $\mathrm{O}$ & $\mathrm{H} 18$ & 2.1 & \multirow{4}{*}{ Tyr323, His170, Ser205 } & \multirow{4}{*}{ Tyr323, Ser205, Met328, Gly325 } \\
\hline & & Thr326 & $\mathrm{HN}$ & $\mathrm{O} 2$ & 2.4 & & \\
\hline & & Asn261 & HD22 & 01 & 2.0 & & \\
\hline & & Ser327 & $\mathrm{HN}$ & $\mathrm{O} 2$ & 2.0 & & \\
\hline & & Asn261 & HD22 & $\mathrm{O} 3$ & 2.0 & & \\
\hline PMSF & -37.64 & Thr326 & $\mathrm{HN}$ & $\mathrm{O} 4$ & 2.2 & $\begin{array}{l}\text { ser203, Gly 206, Aspis8, ser231, } \\
\text { Asn324, Met328 }\end{array}$ & Asn324, Gly325 \\
\hline & & Ser327 & $\mathrm{HN}$ & $\mathrm{O} 4$ & 2.0 & & \\
\hline
\end{tabular}

The table shows the Ligand (as amino acid name; column 1), Docking score for each amino acid ligand in the active site of ASP, the H-bonds between each amino acid ligand and amino acids of ASP where the $\mathrm{H}$-bond forming atoms are represented by their respective number in the corresponding ligand (either ASP amino acid or ligand amino acid). Finally, the hydrophobic interactions and van der Waals interactions made by the amino acid residues (along with their sequence number) of ASP are also shown

\section{Conclusion}

Current study highlighted the biochemical properties, secondary structure, catalytic potential of a serine protease from Bacillus tequilensis. The study determined the binding affinity, substrate specificity and substrate recognition pattern of the modelled serine protease with the keratin and casein enriched residues. Based on these findings, we can safely assume the keratinolytic and caseinolytic potential of this ASP. Ser327, Asp138, Asn261 and Thr326 were found important residues involved in binding and catalysis, suggesting that modification of residues at catalytic triad may further enhance its catalytic potential. 
A

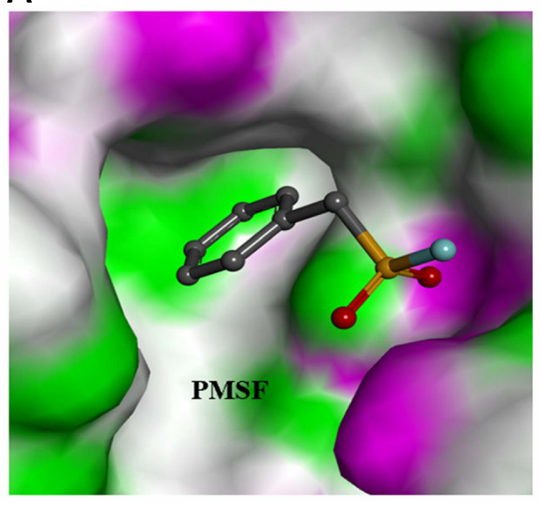

B

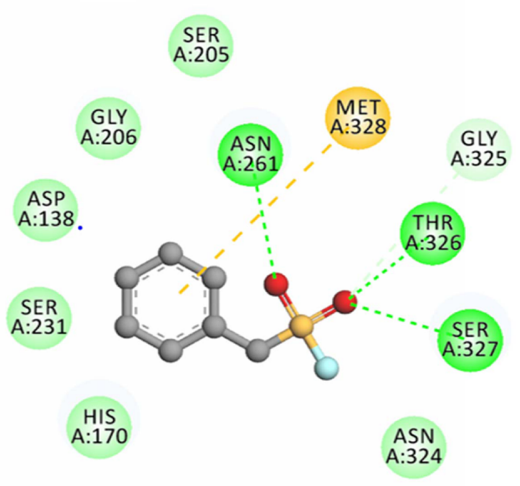

Fig. 5. Molecular orientation and binding pattern of PMSF with ASP. (A) Shows the 3D orientation of PMSF in the substrate binding site of ASP. (B) Depicts the 2D interactions pattern of PMSF and ASP. The interacting residues of ASP are portrayed and labelled. $\mathrm{H}$-bonds are depicted as dashed lines.

\section{Acknowledgments}

The authors acknowledge Higher Education Commission, Pakistan for the provision of funds for this study through TDF Grant No. 02-078 (awarded to corresponding author) and for Indigenous Ph.D. fellowship (awarded to first author).

\section{Conflict of Interest}

The authors have no financial conflicts of interest to declare.

\section{References}

1. Khan Z, Shafique M, Nawaz HR, Jabeen N, Naz SA. 2019. Bacillus tequilensis ZMS-2: A novel source of alkaline protease with antimicrobial, anti-coagulant, fibrinolytic and dehairing potentials. Pak. J. Pharm. Sci. 32:1913-1918.

2. Bose A, Chawdhary V, Keharia H, Subramanian RB. 2014. Production and characterization of a solvent-tolerant protease from a novel marine isolate Bacillus tequilensis P15. Ann. Microbiol. 64: 343-354.

3. Zaraî Jaouadi N, Rekik H, Ben Elhoul M, Rahem FZ, Hila CG, Ben Aicha HS, et al. 2015. A novel keratinase from Bacillus tequilensis strain Q7 with promising potential for the leather bating process. Int. J. Biol. Macromol. 79: 952-64.

4. Gupta R, Beg QK, Lorenz P. 2002. Bacterial alkaline proteases: molecular approaches and industrial applications. Appl. Microbiol. Biotechnol. 59: 15-32.

5. Annamalai N, Rajeswari MV, Balasubramanian T. 2014. Extraction, purification and application of thermostable and halostable alkaline protease from Bacillus alveayuensis CAS 5 using marine wastes. Food Bioprod. Process. 92: 335-342.

6. Rao MB, Tanksale AM, Ghatge MS, Deshpande W. 1998. Molecular and biotechnological aspects of microbial proteases. Microbiol.
Mol. Biol. Rev. 62: 597-635.

7. Alemu F. 2015. Isolation and screening of protease enzyme producing bacteria from cheese at Dilla University, Ethiopia. Int. J. Food. Sci. Nutr. 4: 234-239.

8. Shavandi A, Silva TH, Bekhit AA, Bekhit AE. 2017. Keratin: dissolution, extraction and biomedical application. Biomater. Sci. 5: 1699-1735.

9. Burkhard P, Stetefeld J, Strelkov, Sergei V. 2001. Coiled coils: a highly versatile protein folding motif. Trends Cell Biol. 11: 82-88.

10. Horne DS. 2006. Casein micelle structure: models and muddles. Curr. Opin. Colloid Interface Sci. 11: 148-153.

11. Su D, Zhong Q. 2016. Formation of thymol nanoemulsions with combinations of casein hydrolysates and sucrose stearate. J. Food Eng. 179: 1-10.

12. Alongi J, Carletto RA, Bosco F, Carosio F, Blasio AD, Cuttica F, et al. 2014. Caseins and hydrophobins as novel green flame retardants for cotton fabrics. Polym. Degrad. Stabil. 99: 111-117.

13. Rafiq S, Huma N, Pasha I, Sameen A, Mukhtar O, Khan MI. 2016. Chemical composition, nitrogen fractions and amino acids profile of milk from different animal species. Asian-Australas. J. Anim. Sci. 29: 1022-1028.

14. Trott O, Olson A. 2010. AutoDock Vina: improving the speed and accuracy of docking with a new scoring function, efficient optimization, and multithreading. J. Comp. Chem. 31: 455-461.

15. Abraham MJ, Murtola T, Schulz R, Smith JC, Hess B, Lindahl E. 2015. GROMACS: high performance molecular simulations through multi-level parallelism from laptops to supercomputers. SoftwareX. 2: 19-25.

16. Gasteiger E, Hoogland C, Gattiker A, Duvaud SE, Wilkins MR, Appel RD, et al. 2005. Protein identification and analysis tools on the expasy server. pp. 571-607. 11th Ed. Totowa NJ Hum Publication.

17. Bendtsen JD, Nielsen H, von Heijne G, Brunak S. 2004. Improved prediction of signal peptides: SignalP 3.0. J. Mol. Biol. 340: 783-95. 
18. Kelley LA, Mezulis S, Yates CM, Wass MN, Sternberg MJE. 2015. The phyre2 web portal for protein modeling prediction and analysis. Nat. Prot. 10: 845-858.

19. Huang J, Rauscher S, Nawrocki G, et al. 2017. CHARMM36m: An improved force field for folded and intrinsically disordered proteins. Nat. Methods 14: 71-73.

20. Wiederstein M, Sippl MJ. 2017. Prosa interactive web service for the recognition of errors in three dimensional structures of proteins. Nucleic Acid Res. 35: 407-410.

21. Sippl MJ. 1993. Recognition of errors in three dimensional structures of proteins. Proteins 17: 355-362.

22. DePristo MA, de Bakker PIW, Johnson RJK, Blundell TL. 2015. Crystallographic refinement by knowledge-based exploration of complex energy landscapes. Structure 13: 1311-1319.

23. Verdonk ML, Cole JC, Hartshorn MJ, Murray CW, Taylor RD. 2003. Improved protein-ligand docking using GOLD. Proteins 52: 609623.

24. Rahimnahal S, Shams M, Tarrahimofrad H, Mohammadi Y. 2020. Analysis to describe the catalytic critical residue of keratinase mojavensis using peptidase inhibitors: A docking-based bioinformatics study. J. Bas. Res. Med. Sci. 7: 13-28.

25. Kandasamy S, Duraisamy S, Chinnappan S, Balakrishnan S, Thangasamy S, Muthusamy G, et al. 2018. Molecular modeling and docking of protease from Bacillus sp. for the keratin degradation. Biocatal. Agric. Biotechnol. 13: 95-104.

26. Sulaiman NA, Mahadi NM, Ramly NZ. 2017. Substrate binding site of protease from Bacillus lehensis $\mathrm{G} 1$ by molecular docking. J. Academia UiTM. 5: 36-43.

27. Jayalakshmi P, Krishnamoorthy G, Kumar R, Sivaman P. 2011.
Docking conformation of Bacillus licheniformis keratinase enzyme and PMSF ligand T. Drug Invent. Today 3: 200-202.

28. Shaikh M, Shafique M, Naz SA, Jabeen N. 2019. Streptomyces sp. MM-3 from rhizosphere of Psidium Guajava: A potential candidate for protease with dehairing properties. Pak. J. Bot. 51: 735742.

29. Kuntzel A, Stirtz T. 1958. Hair root studies. J. Am. Leather Chem. Assoc. 53: 445-466.

30. Huang Q, Peng Y, Li X. 2003. Purification and characterization of extracellular alkaline serine protease with dehairing function from Bacillus pumilis. Curr. Microbiol. 43: 169-173.

31. Zambare VP, Nilegaonkar SS, Kanekar PP. 2007. Production of an alkaline protease by Bacillus cereus MCM B-326 and its application as a dehairing agent. World J. Microbiol. Biotechnol. 33: 15691574.

32. Thanikaivelan P, Rao JR, Nair BU, Ramasami T. 2004. Progress and recent trends in biotechnological methods for leather processing. Trends Biotechnol. 22: 181-188.

33. Sivasubramanian S, Murali MB, Rajaram A, Puvanakrishna R. 2008. Ecofriendly lime and sulfide free enzymatic dehairing of skins and hides using a bacterial alkaline protease. Chemosphere 70: 1015-1024.

34. Sattar H, Aman A, Javeed U, Qadar SAU. 2018. Polyacrylamide beads: Polymer entrapment increases the catalytic efficiency and thermal stability of protease. Mol. Catal. 446: 81-87.

35. Miao J, Liu G, Luo Z, Xia Z, Liu F, Chen Y, et al. 2016. Calcium-binding peptides isolated from casein hydrolysates enhances intestinal calcium uptake. FASEB J. 30: 690-1015. 